\title{
Some Thoughts on the Establishment of Xishuangbanna-North Laos Cross-border Tourism Cooperation Zone
}

\author{
Wang Wenhui \\ School of Public Administration \\ Yunnan University of Finance and Economics \\ Kunming, China
}

\author{
He Youlin \\ School of Tourism and Geographic Science \\ Yunnan Normal University \\ Kunming, China
}

\begin{abstract}
China is accelerating its implementation of the "One Belt and One Road" strategy, Laos has joint the WTO which certainly will speed up its pace of opening up and an allaround transportation network is being rapidly built between China and Laos. In such a context, the development of tourism in Xishuangbanna and north Laos will enter a golden period. This paper suggests that both China and Laos should seize this opportunity and jointly build Xishuangbanna-North Laos Crossborder Tourism Cooperation Zone, and analyzes the advantages and conditions that are available to support the establishment of Xishuangbanna-North Laos Cross-border Tourism Cooperation Zone, and the impeding factors that may be encountered. Based on spatial structure and cooperation main body, this paper proposes the idea of constructing the cooperation mode, which is to adopt a development mode of "from point to axis, and then to circle" as for spatial structure, and let the government take the lead in the initial stage while the market in the middle and later stages of construction as for cooperation main body.
\end{abstract}

Keywords-Xishuangbanna, North Laos, Tourism, Regional Cooperation

\section{INTRODUCTION}

On December 2, 2015, the 40th anniversary of the founding of Laos, China-Laos Railway officially started construction. China-Laos Railway is a major strategic cooperation project between China and Laos, and an important infrastructure connecting the two countries. The authors suggest that China and Laos should seize this great opportunity brought by China's accelerating the implementation of its "One Belt, One Road" strategy, Laos' entry into the WTO which speeds up its pace of opening up, and accelerated building of an all-around transportation network between China and Laos, to establish Xishuangbanna-North Laos Cross-border Tourism Cooperation Zone, incorporate Xishuangbanna Dai Autonomous Prefecture in Yunnan of China, and the five provinces in north Laos (namely, Luang Prabang Province, Luang Namtha Province, Oudomxay Province, Bokeo Province and Phongsaly Province) into the cooperation zone and explore and find a new way to accelerate opening up along the border area to promote crossborder cooperation and development of tourism, help people in the border area to get rich and safeguard the safety and peace in the border area.
Literature review: the authors have searched papers that have a title containing the phrase of "cross-border tourism cooperation zone" on www.cnki.net, and only found six pieces of such papers. Among these papers, three pieces conduct general theoretical discussion about cross-border tourism cooperation, and the other three pieces are analyses about establishing China-Russia, China-Russia-North Korea or China-Vietnam cross-border tourism cooperation zones, and no such papers that are about establishing a cross-border tourism cooperation zone between Yunnan Province, particularly Xishuangbanna, and Laos (including the north part of Laos) were found. And the authors have searched papers that have a title containing the phrase of "cross-border tourism cooperation" on www.cnki.net, and only found 16 pieces of such papers. Among these papers, there are no papers concerning Laos. In addition, we have searched papers that have a title containing such words as "Laos", "tourism" and "cooperation" on www.cnki.net, and only found two pieces of such papers, and they are A Study about A Tourism Cooperation Mechanism between Yunnan and Laos from the Perspective of Regional Tourism Development (Chen Jian 2013) and A Discussion about the Development of Tourism Economy in Yunnan and Laos from the Perspective of Regional Cooperation on Tourism ( Liao Yixin 2014). Based on these efforts, we come to the conclusion that relatively few studies have been conducted about cross-border tourism cooperation zone, and we have found no studies that have been conducted about establishment of a cross-border tourism cooperation zone between Xishuangbanna and north Laos.

\section{CONCEPT AND SIGNIFICANCE}

Cross-border tourism cooperation zone refers to a certain area of territory that is designated by two or multiple participating parties in the border area of two or multiple neighboring countries, and jointly planned and managed by both or multiple parties, where the tourism industry is the backbone industry and tourist elements concentrate as a result of free movement of tourists and tourist elements1. Crossborder cooperation zone is a new way to realize liberalization

Xing Ling (2015), An Innovative Model of Regional Tourism Development: Cross-border Tourism Cooperation Zone, Academic Exploration, Issue No.9, Page 72. 
of trade and integration of economy in the tourism industry, and also can be viewed as a cross-border tourism trade area, which can not only promote development of goods trade, but also bring the booming of service trade2.

Building a cross-border tourism cooperation zone will strengthen close cooperation between or among the participating two or more parties, increase tourism products, extend tourist lines, meet various consumption needs of visitors and promote further development of the tourism industry; it may also take tourism as a bridge and carrier, promote bilateral and multilateral exchange and cooperation, explore and find an effective model of cross-border regional cooperation, build and increase mutual trust, promote the implementation of allaround cooperation, and achieve mutual benefit and win for all; it may also promote economic and social development in the border areas and hinterland of every participating parties, increase employment, promote income increase of residents in the border areas, strengthen safety and peace in the areas, and improve previous unfavorable situation of local geo-economy. In addition, in a peaceful international environment, crossborder tourism cooperation zones will serve as a booster for improving the relationship between participating countries; when the relationship between the two countries gets tense or tends to get tense, the somewhat mutually-dependent relationship that has been established as a result of the crossborder tourism cooperation zone may serve as a buffer for international relations. In a word, building cross-border tourism cooperation zones is of great significance.

\section{Advantages And Conditions}

\section{A. Apparent geographic advantages and convenient traffic conditions}

Xishuangbanna borders on North Laos, and the borderline is as long as $677.8 \mathrm{~km}$. Xishuangbanna constitutes a frontline and portal that connects Laos and China's hinterland. Xishuangbanna Mengla (Mohan) Key Development and Opening Up Pilot Zone is a special border area that is designated by China to open up to Laos, and Mohan port is China's only national-level port that connects China and Laos, and the Mohan-Boten Cross-border Economic Cooperation Zone connects the two countries together by economic ties. Xishuangbanna backs on China's hinterland, and north Laos neighbors several South Eastern Asian countries. Xishuangbanna and North Laos both are relatively close to the main source area of visitor customers, and there is a natural geographic advantage for cross-border tourism cooperation between the two areas.

Xishuangbanna and North Laos are connected by waterways, highways, airways and a high-speed railway under construction. Firstly, as for highways, the express highway that connects Kunming with Jinghong City in Xishuangbanna has opened to traffic for many years, and the highway between Xiaomengyang (near Jinghong) and Mohan Port is being rebuilt and expanded into an express highway. Out of China at

${ }^{2}$ Li Fei (2013), Cross-border Tourism Cooperation Zone: A New Model of Border Area Tourism Development under Exploration, Science of Tourism, Issue No.10, page 15 .
Mohan and into Laos at Boten, there are highways extending to different provinces in the north of Laos, in which Mohan is just $280 \mathrm{~km}$ from Luang Prabangn Province. Thailand, Cambodia and Vietnam can be reached through Laos; from the port of Daluo in Xishuangbanna, Burma can be reached. Secondly, as for waterways, Lantsang River-Mekong River waterway is a convenient international waterway, which is called "the Danube in the East", and now plays an increasingly important role. Through the Lantsang-Mekong River waterway, you can go from Xishuangbanna right to Luang Prabang by boat or the other way round. Thirdly, as for airways, Xishuangbanna International Airport has opened about 20 domestic air routes, in which there are many international air routes flying to Vientiane and Luang Prabang of Laos, and Bangkok and Chiengmai of Thailand, and other places. Fourthly, as for railway, this paper has introduced at the beginning the ChinaLaos Railway currently under construction. This railway will run through Xishuangbanna, North Laos (including Luang Prabang) and go right to Vientiane; and in the future, it may be further extended to Bangkok of Thailand (namely, ChinaThailand railway), Malaysia and Singapore, and constitutes a central line of pan-Asia railways.

\section{B. Unique yet complementary tourism resources}

Xishuangbanna has very abundant tourism resources, and is called "the world of plants" and "the world of animals". The charming and gentle subtropical landscape, the abundant plant and animal resources and the ancient and rich ethnic culture are elegantly integrated together in Xishuangbanna, which makes Xishuangbanna a key national natural conservation area and a scenic area well-known both at home and abroad. Xishuangbanna has its unique features in such natural and cultural aspects as regional culture, ethnic flavor, tropical rain forest, ornamental plants and wildlife. In addition, Xishuangbanna is an area where many different ethnicities reside together with the Dai people constituting the main population, and other ethnicities include Hani, Yi, Lahu, Bulang, Jinuo, Yao, Miao, Hui, Wa, Zhuang, Jingpo and other minorities, as well as Kemu People, Laopin People and Bajia People whose ethnicities have not been determined yet. In Xishuangbanna, the minorities account for over $70 \%$ of the whole population. The unique ethnic customs and living ways of different ethnicities, the long and glorious history and culture, the rich and colorful clothes and unique food culture, including the newly developed Wanda International Holiday Resort (including Wanda Theme Fairyland), constitute a unique cultural tourism resource in Xishuangbanna.

North Laos borders on China (mainly Xishuangbanna). In North Laos, the climate is mild and comfortable, and there are many high chains of mountains going up and down, covered with dense forests, which forms a splendid natural landscape; in addition, this area has abundant valuable cultural heritages and places of historic interest and scenic beauty. In Luang Prabang Province, there is the relic of the ancient city of Luang Prabang, which is recognized as a world cultural heritage, and there are such scenic spots as the National Museum, Xieng Thong Temple, Wat Mai Suwannaphumaham temple, Weichun temple and Kuang Si Falls; Luang Namtha Province has such scenic spots as Nam-Ha National Protected Area and Luang 
Namtha museum; Oudomxay Province is home to the Mekong riverside, the gentle and quiet Pakbeng, and the important courier station Udomxai. In addition, Bokeo Province is also in the north part of Laos, through which the Mekong River runs. Bokeo Province borders on Burma and Thailand to its north and west respectively. Phongsali Province borders on China to its west and north and borders on Vietnam to its east. These two provinces also have unique features. The ethnicities in north Laos have a long history and a great variety of customs, and are very hospitable; besides, their human tourism resources and natural tourism resources both have distinct features, and are very appealing to visitors.

Xishuangbanna and North Laos are connected in their mountains and rivers, and their people are also deeply connected. Their main minority populations all believe in Hinayana Buddhism and their cultures have many things in common. Nevertheless, due to the particularity and complexity in their geographic environment, social townscapes, and historical and cultural aspects, they have their own unique features, and are complementary at the same time. For each other, one can experience and feel some exotic flavor both in Xishuangbanna and North Laos. Such complementariness not only helps provide abundant resource reserve for establishing a cross-border tourism cooperation zone, but also boasts huge realistic and potential development space.

\section{The relationship between China and Laos and their respective policies support the deepening of tourism cooperation}

Ever since the relationship between China and Laos was normalized in 1989, the relationship between the two countries has been comprehensively restored and developed, their friendly exchanges and cooperation in politics, economy, military, culture, health care and other areas have been constantly deepened, and the two countries have maintained close coordination and cooperation in many international and regional affairs. China has undertaken to build many fundamental transportation projects in Laos, which lays a foundation for the development of Laos' transportation for its tourism industry. In 1996, the two countries signed an agreement for cooperation on tourism, and explored cooperation on tourism.3 In 2004, China and Laos signed the Memorandum of Understanding on Tourism, which provides an important precondition for the two countries to strengthen cooperation in investment and tourism.4 Yunnan Province and North Laos have conducted a series of cooperation, including cross-border cooperation on tourism. For example, the two parties jointly offer China-Laos border post visit, self-driving tour, Lantsang River-Mekong River boat ride, and other crossborder tourism cooperation, and these cooperation projects overall have been smoothly implemented.

${ }^{3}$ Liao Yixin (2014), A Discussion about the Development of Tourism Economy in Yunnan and Laos from the Perspective of Regional Tourism Cooperation, Times Finance, the later part of Issue No.6, page 85.

${ }^{4}$ Liao Yixin (2014), A Discussion about the Development of Tourism Economy in Yunnan and Laos from the Perspective of Regional Tourism Cooperation, Times Finance, the later part of Issue No.6, page 85.
China's "One Belt and One Road" strategy positions Yunnan as a radiating center targeting at South Asia and Southeast Asia. Yunnan is becoming from the back land of external opening up to a front line, and certainly will play a more important role in China's opening up, transportation layout and other relevant overall strategies. Laos is a country along the "One Belt and One Road", and also one of the key countries to which Yunnan, especially Xishuangbanna Autonomous Prefecture aims to radiate its influence. Several Opinions on Promoting Reform and Development of the Tourism Industry (Guofa No. (2014)31) issued by the State Council specifically proposes to promote regional integration of tourism, further promoting external joint venture and cooperation, support tourist enterprises meeting certain conditions to "go out" and actively develop international market, improve domestic and international regional tourism cooperation mechanism, establish tourist traffic, information and service networks, and strengthen regional sharing of customer sources so as to establish a regional tourism cooperation body that is practical, efficient and mutually beneficial. Resolving around the Silk Road Economic Belt and the building of the 21 st century Maritime Silk Road, and under the framework of such regional or sub-regional cooperation mechanisms as ASEAN-Mekong River flowing through areas cooperation, and the larger Mekong River Sub-regional Economic Cooperation, it is advised to adopt entry and exit policies that are favorable for tourism in border areas so as to promote regional tourism cooperation between China and Southeast Asia, South Asia and other regions. As mentioned before, the cooperation mechanisms under the many bilateral and multilateral frameworks that have been established or set up between China and Laos have created favorable conditions for the establishment of Xishuangbanna-North Laos Crossborder Tourism Cooperation Zone.

In the recent years, the Laos' government has attached great importance to tourism and made great efforts to develop its tourism industry. For example, it has promulgated several policies and regulations to promote development of the tourism industry, and is continuously improving its tourism infrastructure. At present, the tourism industry is playing an important driving role for development of the country's overall economy, and tourist income has become one of the important sources of financial revenue of Laos' government. In February 2013, Laos officially joined the WTO, which will help Laos deepen its global and regional economic connection, and carry out tourism cooperation with relevant countries, including China, and will promote development of its tourism industry.

\section{CONSTRAINTS}

As a new form and new carrier of cross-border tourism and international tourism cooperation, cross-border tourism cooperation zone is inevitably faced with some constraints during the course of exploration and promotion, mainly including:

(1) It is vulnerable to the influence and constraints of politics and policies. Cross-border tourism cooperation zone may be subject to influence and constraints from geographical politics, international relations, economic and trade cooperation as well changes in policies of the country. Therefore, it needs 
to fend external threats off the home country and promote the legitimate flow of cross-border workers, goods and funds. National boundaries "are to be closed and open as well" (Wang Jimei, 2009), Cross-border tourism cooperation zone integrates together the shielding function and communication function of boundaries5. For the sake of national security, the existing entry-exit management policies and boundary management system of all countries are rigidly binding upon the free exchanges of persons, vehicles and factors of production. Therefore, convenient entry and exit requires unified coordination at the national level, and is beyond the capability of local governments 6 , which imposes challenges to the promotion of cooperation zone construction and management coordination after establishment thereof.

(2) Infrastructure and supporting resources need improvement. Areas covered by the cross-border tourism cooperation zone proposed by the authors, although changing from the back to the front of opening up, are relatively imperfect in infrastructure and insufficient in talents and technologies and other production factors as they have long been at the end of national economic and social development. In particular, tourism development investment in north Laos is far from adequate with bad road conditions, narrow mobile communication signal coverage and tourist reception ability to be further improved. Given the insufficient investment capacity of Laos, these problems should be solved relying on innovative thinking.

(3) Investment main bodies and the way of profit distribution are special. Currently, tourism cooperation between China and Laos are mainly advocated by the government involving little participation from large enterprises. Enthusiasm of enterprises, as the market main body, needs to be further mobilized. The special nature of cross-border tourism cooperation zone imposes different requirements on institutions and enterprises responsible for development and construction from those on domestic ordinary tourist areas (or spots). Enterprises are more prudent in consideration of the investment risks, and the profit distribution among countries remains a problem requiring long-term negotiation 7 .

(4) There is a lack of unified implementation standards and consistent implementation. No unified guidelines and standards of implementation have been established for tourism cooperation between Xishuangbanna and North Laos. At present, information disclosure is not transparent on tourism cooperation between the two parties, the outside knows little of the particular implementation status of most cooperation projects advocated by the government, no supervision system with rules and regulations as the core has been established and the specific implementation status of cooperation projects is

Li Fei (2013), Cross-Border Tourism Cooperation Zone: Exploration into the New Mode of Development of Cross-Border Tourism, Tourism Science, Issue 10, Page 19.

${ }^{6}$ Li Qinglei, Yang Lujia (2015), Thinking on Cross-Border Tourism Cooperation Zone, China Tourism, December 14, 2015, Version C02.

${ }^{10}$ Li Qinglei, Yang Lujia (2015), Thinking on Cross-Border Tourism Cooperation Zone, China Tourism, December 14, 2015, Version C02. subject to no supervision 8. There are other problems in Xishuangbanna and North Laos, such as slow working efficiency and work executive force and promotion force to be further strengthened.

What's more, language communication hinders the construction of Xishuangbanna-North Laos Cross-border Tourism Cooperation Zone where each party should be equipped with talents familiar with the language and culture of the other party. The above factors constrain the construction of cross-border tourism cooperation zone, and should be solved through concerted efforts from both China and Laos.

\section{Cooperation Modes--Construction of COOPERATION MODE BASED ON SPATIAL STRUCTURE}

As an important field in tourism geography research, spatial structure of regional tourism is the spatial status of tourism activities reflected by spatial pattern, aggregation degree formed by parties in regional cooperation through interaction in space and is a reflection of tourism activities in the geographic space 9. Based on the five kinds of spatial structure cooperation modes put forward by Yang Rongbin (2006) 10, the spatial structure suitable for Xishuangbanna-North Laos Cross-border Tourism Cooperation Zone is mainly "core-edge" development mode, "point- axis" development mode and network mode. Since regional tourism cooperation is affected temporal dimension, spatial dimension and other aspects of the regional tourism development, cooperation development mode remains in a dynamic process of evolution and development 11 From the point of views of geographical space of Xishuangbanna-North Laos Cross-border Tourism Cooperation Zone, tourism activities will be carried out mainly focusing on core scenic spots in Xishuangbanna Scenic Area (with Jinghong as the center), core scenic areas in North Laos represented by Luang Prabang scenic spot, Mohan-Boten Cross-Border Economic Cooperation Zone (including port), along the Jinghong-Luang Prabang, along the LancangMekong River and the future China-Laos Railway, and supported by the existing three-dimensional transportation axis to generate radiation and agglomeration effect on the tourism industry. From the point of view of current development position of China-Laos cross-border tourism cooperation, regional tourism cooperation should be realized in all dimensions and in depth from the spatial development pattern, and "point-axis-cycle" mode should be adopted for the spatial development pattern. Regional tourism cooperation adopting such mode generally features a gradual promotion process

\footnotetext{
${ }^{8}$ Liao Yixin (2014), Discussion of Yunnan and Laos Tourism Economic Development from the Point of View of Regional Tourism Cooperation, Times Finance, Issue of Late $6^{\text {th }}$, Page 85.

${ }^{9}$ Liu Yun, Zhang Mengyao (2014), Discussion on Construction of ChinaBurma Cross-Border Tourism Cooperation Development Mode, Inquiry into Economic Issues, Issue 6, Page 129

${ }^{10}$ Yang Rongbin, Zheng Jianyu, Cheng Jinlong, Research on Regional Tourism Cooperation Structure [J], Geography and Geographic Information Science, 2005, 21 ( 5) : 95- 98.

${ }^{11}$ Liu Yun, Zhang Mengyao (2014), Discussion on Construction of China-Burma Cross-Border Tourism Cooperation Development Mode, Inquiry into Economic Issues, Issue 6, Page 129
} 
where "point" relies on "axis" and "point-axis" spreads to "cycle"12.

(1) Point. Make Xishuangbanna Scenic Area, Luang Prabang, Mohan-Boten Cross-Border Economic Cooperation Zone as the main growth poles. Both Xishuangbanna Scenic Area and Luang Prabang are world famous tourist spots. As mentioned above, they both have abundant natural tourism resources and cultural tourism resources, where tourism remains the leading industry. In the context of economic globalization and regional economic integration, tourism of Xishuangbanna Scenic Area and Luang Prabang is expected to keep steady growth and play a role as an organizer and leader in regional economic growth. Xishuangbanna Scenic Area and Luang Prabang are qualified as the growth poles in Xishuangbanna and North Laos respectively and form the economic centers through geographic spatial agglomeration of tourism and innovative industries as the leading industries and related sectors.

Mohan-Boten Cross-Border Economic Cooperation Zone growth pole is the product of bilateral trade cooperation. It is outward and transnationally linked, and its generation and development rely on the progress of internal linkage and external expansion. Mohan-Boten Cross-Border Economic Cooperation Zone will gradually be built into a transport hub connecting the southwestern area and ASEAN countries and an industry agglomeration highland with the completion of Kunming-Bangkok Highway, active promotion of Pan-Asia railway line and renovation of upper Mekong River waterway. From such growth pole, mainland China is accessible northwards and North Laos is accessible southwards, utilization of domestic and foreign resources and markets can be promoted, external introduction and internal linkage can be boosted, bilateral cooperation can be deepened, and the formation of new advantages of cross-border tourism cooperation can be accelerated so as to further develop "boundary maker tour", "national culture tour", "tropical scenery tour", "exotic tour", "cross-border road self-driving tour" and other China-Laos boarder tourism products.

From spatial structure, therefore, Xishuangbanna Scenic Area, Luang Prabang, Mohan-Boten Cross-Border Economic Cooperation Zone can become three key "points" and also three main growth poles of the proposed cross-border tourism cooperation zone, which serves as the organizer in regional economic activities relying on their domination effect, multiplier effect, polarization and diffusion effect 13 .

(2) Axis. Make the waterway, road and air route transportation lines between Jinghong of Xishuangbanna and Luang Prabang a development belt, which is a connecting link between points and cycles. Based on the existing Xishuangbanna-Luang Prabang waterway, road and air routes and the railway to be completed, traffic conditions should be further improved, and the transportation network layout will be

\footnotetext{
${ }^{12}$ Zhang Heqing, Wang Leilei, Application of Radiation Theory in Regional Tourism Cooperation [J], Journal of Guangzhou University (social science version), 2010, 9(12):36-40.

${ }^{13}$ Economic Geography, edited by Li Xiaojian, 2006, published by Higher Education Press, Page 209
}

optimized to promote regional interactive development. A cross-border tourism cooperation corridor should be constructed and the construction of Xishuangbanna-North Laos Cross-border Tourism Cooperation Zone should be developed deeply based on the road and railway axis of Jinghong of Xishuangbanna-Mohan-Boten Cross-Border Economic Cooperation Zone-Luang Prabang, air route axis of Jinghong of Xishuangbanna-Luang Prabang and axis of Lancang-Mekong River (Jinghong to Luang Prabang air route). The cities, towns and cross-border economic cooperation zones (including ports) along the way can be connected through waterway, road and air route transportation lines to form the cross-border tourism routes and further drive the economic and social development along the way.

(3) Circle. Key efforts should be made for the construction of three tourism cycles into radiating areas focusing on the three growth poles, namely Xishuangbanna Scenic Area, Luang Prabang and Mohan-Boten Cross-Border Economic Cooperation Zone. Cycles should be radiating areas with each of the three growth poles as the core area of each cycle. Largesize tourism cooperation agglomeration11 with outward expansion and radiation should be formed through the relatively convenient three-dimensional transport network and abundant tourism resources surrounding the core areas. Xishuangbanna Scenic Area, with Jinghong as its center, radiates to Menghai and adjacent areas; Luang Prabang, with ancient city of Luang Prabang as its center, radiates to Luang Prabang Province, Oudomxay Province, Bokeo Province and other adjacent areas; Mohan-Boten Cross-Border Economic Cooperation Zone, with Mohan and Boten Ports as its center, radiates to Mengla area of Xishuangbanna, Louang Namtha Province and Phôngsali Province and adjacent areas of Laos.

\section{Policy Suggestions}

In order to promote construction of Xishuangbanna-North Laos Cross-border Tourism Cooperation Zone, the authors put forward the following suggestions:

\section{A. Build cooperation mechanism and optimize support policies.}

China and Laos should maintain traditional friendly relations between the two countries and parties to further enhance mutual trust, deepen cooperation and create important political and economic environments for cross-border tourism cooperation. At the same time, a Chinese-Laos cross-border tourism cooperation organization should be established to shoulder the responsibility for management and coordination of major issues in tourism cooperation between the two parties including Xishuangbanna-North Laos Cross-border Tourism Cooperation Zone. Within the mechanism framework of the existing Working Group of Yunnan-North Laos Cooperation, Xishuangbanna-North Laos Cross-border Tourism Cooperation Zone Coordination Team should be set up, whose responsible person and members should be principals of relevant governmental departments, such as Yunnan Provincial Tourism Bureau, relevant departments of Xishuangbanna Prefecture, relevant departments of five northern provinces of Laos. This Team should be dedicated to construction, coordination and management of the cross-border tourism cooperation zone and 
joint formulation of unified implementation rules and standards for cross-border tourism cooperation. The above cooperation organization and mechanism should regularly exchange ideas on related affairs, jointly develop development plans and solve practical problems. When conditions are met, Management Committee of Xishuangbanna-North Laos Cross-border Tourism Cooperation Zone should be set up, principals of which should be designated by both China and Laos. Policies governing currency exchange of the two countries, entry and exit management of persons, vehicles, goods and articles, supervision on cross-border tourism market should be improved. Development policies conducive to cross-border tourism industry aggregation should be formulated and improved to attract investment between these two countries and other countries, arouse the enthusiasm of enterprises for investment or participation, and safeguard the legitimate rights and interests of the parties involved. Relevant departments of Xishuangbanna and North Laos and their working staff should improve their working efficiency, executive force and promotion force.

\section{B. Strengthen survey planning based on local situations by referring to international experience.}

Professional institutions and individuals should be encouraged to conduct in-depth survey and research on the construction of the cross-border tourism cooperation zone, based on actual situations of Xishuangbanna and North Laos, and focus on feasibility, construction content, product development, operating subjects, management mode, policy support, risk control and related issues to form systematical, innovative and guiding research findings and provide a reference for government decision-making and corporate investment. At the same time, exchanges and cooperation should be conducted with relevant countries in the field of cross-border tourism cooperation zone construction to draw on their successful experience 12 in cross-border tourism cooperation zones, such as US-Canada Watertown-Glacier International Peace Park, Alps, Kavango Zambezi Transfrontier Conservation Area in Africa. Feasible development plans should be prepared to define the overall idea, development goals and main tasks of the construction of the cross-border tourism cooperation zone, make clear the overall layout, key areas and core areas, selected priority projects and support content, and work out the security measures and recent action plans for the development of the cross-border tourism cooperation zone 14.

\section{Strengthen infrastructure construction and improve traffic conditions, communications and information network.}

At present, Xishuangbanna has relatively good tourism infrastructure conditions which also need optimization, though. For instance, during the Spring Festival in 2016, tourists encountered a dilemma where they could not get in, around and out in many scenic spots in Xishuangbanna. Economic basis is relatively backward in North Laos and parts of the roads are in bad condition, and mobile communications do not work well in some areas. As for wifi that the general public is heavily

${ }^{14}$ Li Qinglei, Yang Lujia (2015), Thoughts on Cross-Border Tourism Cooperation Zone, China Tourism, December 14, 2015, Version C02. dependent on, has not covered many places and facilities in Xishuangbanna and North Laos that should have been covered. All these become the bottlenecks of tourism. The government should place more emphasis and solve the above issues by conducting department interaction and multinational cooperation and raising funds from many sources so as to improve tourist reception capacity, provide visitors with more convenient and comfortable environment and improve tourist satisfaction.

\section{D. strengthen the construction of a professional talent team.}

One key to the successful construction of a cross-border tourism cooperation zone construction is to have a professional talent team, including high-level professionals familiar with tourism planning, tourism business, marketing, management and language of the other side. At the same time, various levels of targeted training should be offered to strengthen external, internal, horizontal and vertical learning and communication of the talents, speed up cultivation of compound talents and promote sustainable and healthy development of the crossborder tourism zone.

All in all, tourism is the leading industry for economic development of Xishuangbanna and North Laos. Under the great background of China's "One Belt and One Road" strategy, Yunnan's construction of radiation center targeting at South Asian and Southeast Asia, Laos's access to the WTO, acceleration of opening up, economic globalization and regional economic integration, tourism development of Xishuangbanna and North Laos will enter a golden period. China and Laos should seize the opportunity and make joint efforts to construct Xishuangbanna and North Laos CrossBorder Tourism Cooperation Zone, which is of great significance and practical feasibility, and will be conducive for the two parties to deep cooperation and win-win.

\section{ACKNOWLEDGMENT}

I would like to express my gratitude to all those who helped me during the writing of this thesis. I gratefully acknowledge the help of my collaborator: Mr. Rolin He , who has offered me valuable suggestions in the academic studies. In the preparation of the thesis, he has spent much time reading through each draft and provided me with inspiring advice. Without his patient instruction, insightful criticism and expert guidance, the completion of this thesis would not have been possible.

\section{REFERENCES}

[1] Xing Ling (2015), An Innovative Model of Regional Tourism Development: Cross-border Tourism Cooperation Zone, Academic Exploration, Issue No.9.

[2] Li Fei (2013), Cross-border Tourism Cooperation Zone: A New Model of Border Area Tourism Development under Exploration, Science of Tourism, Issue No.10.

[3] Liao Yixin (2014), A Discussion about the Development of Tourism Economy in Yunnan and Laos from the Perspective of Regional Tourism Cooperation, Times Finance, the later part of Issue No.6.

[4] Li Qinglei, Yang Lujia (2015), Thinking on Cross-Border Tourism Cooperation Zone, China Tourism, December 14, 2015, Version C02.

[5] Liu Yun, Zhang Mengyao (2014), Discussion on Construction of ChinaBurma Cross-Border Tourism Cooperation Development Mode, Inquiry into Economic Issues, Issue 6. 
[6] Yang Rongbin, Zheng Jianyu, Cheng Jinlong, Research on Regional Tourism Cooperation Structure [J], Geography and Geographic Information Science, 2005, 21 ( 5)

[7] Zhang Heqing, Wang Leilei, Application of Radiation Theory in Regional Tourism Cooperation [J], Journal of Guangzhou University (social science version), 2010, 9( 12).

[8] Economic Geography, edited by Li Xiaojian, 2006, published by Higher Education Press.

[9] Wen Xiu, Research on Regional Tourism Cooperation Subjects and Cooperation Path [D], doctoral academic dissertation of Northwest University, 2010: 64.

[10] Liu Yun, Zhang Mengyao (2014), Discussion on Construction of ChinaBurma Cross-Border Tourism Cooperation Development Mode, Inquiry into Economic Issues, Issue 6.
[11] Li Qinglei, Yang Lujia (2015), Thoughts on Cross-Border Tourism Cooperation Zone, China Tourism, December 14, 2015, Version C02. 